\title{
CARLOS CHAGAS - UM ENSAIO SOBRE A IMAGINAÇÃO CRIADORA E A FILOSOFIA DA DESCOBERTA
}

\author{
Francisco Eduardo Rabello * \\ II y a dans tout de l'inexploré \\ Maupassant sobre Flaubert \\ Para aquele que viveu a alegria \\ da criação, nada mais conta \\ Tchekov
}

Tão longe quanto alcança a memória, vejo Carlos Chagas profundamente ligado ao meu ambiente familiar: terá este este escrito, assim, valor de um testemunho. Entre 1910 - data de uma famosa fala de Miguel Pereira e de sua intensa repercussão na casa de meus Pais a 1934, naquela tarde infausta no curso da qual tombava esse grande homem fulminado por uma crise cardíaca - vi, ouvi e participei da saga dessa rara criatura.

\section{"Pasteur l'a révélé \\ On n'aurait rien compris avant qu'il n'eut parlé".}

Com esta epígrafe colada à fachada do discurso com que saudava Chagas em 1910, Miguel Pereira colocava também pela primeira vez, no palco da discussão, uma visada científica do fenômeno da descoberta, já que só os grandes criadores têm o poder de "revelar" para nós todo um mundo que jazia velado e impenetrado. E com isso nos oferecendo sua própria visão do mundo, servidos por aquilo de Heidegger de que " acima da realidade está a possibilidade".

Descoberta - não apenas o encontro com um fato novo. Não o "achado" que tanto surpreenderia o Viking dando nas costas do. Continente Americano, mas a "descoberta" isto é, a verificação de uma hipótese de trabalho como o faria quatro séculos depois, Colombo.

Como só faria Colombo, partejando um Novo Mundo, esse desconhecido, que no auto de Claudel arranca de um bem pensante a confissão de que "o desconhecido é uma coisa sempre desagradável" , e de Colombo a certeza para a posteridade de que "sabia infinitamente mais do que descobrira". E ao cabo de tudo - "no paraíso da idéia" esta outra certeza de que arrancava pelas raizes "as antigas colunas de Conhecido".

Descoberta ainda - com todas as conseqüencias geopolíticas, econômicas e culturais que um ato dessa magnitude anuncia, promove e fertiliza.

Pela mão de Carlos Chagas, uma genial sucessão de fatos provocados, configurando um desses "experimentos da natureza" de que nos fala esse grande imunologista e pensador que é Robert Good, e já em 1508 Leonardo da Vinci: "La natura à piena di ragioni, che non furono mai in esperienza".

Pelo coração de Carlos Chagas - esse mesmo coração que o mataria, um ato de imensa Caridade, ante uma "paisagem pobre, mofina e destorcida", consubstanciada naquela brasileirinha Berenice cuja doença, tocando também o coração do pesquisador, levou-o à transcendência da descoberta. Ciência desinteressada e bemfazeja, essa ciência médica "contaminada de virtudes", na palavra de Charles Nicolle.

Pelo cérebro de Carlos Chagas, o fenômeno da descoberta com todas as consequências que ela traz no seu bojo, o que fez Claude Bernard escrever que "não é o fato $\mathrm{em}$ si que é descoberto, mas a nova idéia que ele produz", e mais adiante que tudo está em "prever e dirigir os fenômenos", diferença radical com o simples achado. Como ainda do mesmo Bernard que "uma idéia nova aparece como uma relação nova ou inesperada que o espírito percebe entre as coisas". E o nosso grande patrício, em pessoa,

Professor Titular de Clrnica Dermatológica da Faculdade de Medicina da Universidade Federal do Rio de Janeiro. 
logo às primeiras páginas de Bernard (sua Introduction): "Quando um mesmo sábio descobre e desenvolve, sozinho, toda uma questão científica".

Nessa linha, o "experimento investigador" - o Forschungsexperiment de Heidegger se apresenta em todàs as suas facetas, em toda a sua grandeza. E neste caso a dinâmica da descoberta já foi contada, é bem conhecida. Em essência, entretanto, dois momentos merecem ser destacados: o primeiro, quando o pesquisador pediu, a uma distância de uns $600 \mathrm{Km} \mathrm{-} \mathrm{em}$ vôo "cego", a inoculação de material do provável transmissor em animal virgem e receptivo; o segundo, quando sob o comando da intuiçãoimaginação, viu-se levado à verificação do fato clínico intuído.

Tanto é certo que "a história de uma obra é a história de um gesto que se completa", e de que "a verdadeira ciência nada suprime, antes procura sempre, olhando de frente e sem perturbar-se com as coisas que ainda não compreende".

Digamos, porém já, antes de mais detida análise do descobrimento, alguma coisa sobre o homem, naquele seu portentoso desinteresse pelos eventos triviais da vida. $E$ também como um desses predestinados a uma curta vida, e que cedo amadurecem para a ciência e para a glória, tal como desses grandes homens disse $H$. $F$. Amiel que "comme la flamme, ne trouvent d'existence que dans la combustion".

Predestinados, como que portadores de um pressentimento de morte prematura curiosa premunição que só ela vale detida reflexão e estudo. Exemplos não faltam na medicina, lembrados Laennec, Oswaldo Cruz e Miguel Pereira, nas letras o nosso Castro Alves, Gérard de Nerval, Rimbaud e Lautréamont, na música os Clássicos exemplos de Mozart e Schubert. E de um desses a palavra bem conhecida de que "os gênios são meteoros que queimam para o bem da humanidade".

Sob outro ângulo, e para isto servir-me-ei da extraordinária trilogia de Carl J. Burckhardt sobre Richelieu, homens desta têmpera na verdade pouco se preocupam com o tempo que
Ihes resta viver, posto que, para eles, a vida como que não tem fim, sendo mais um futuro do que um presente. Aqui citada, Sta. Tereza a Doutora dizendo: "muero, porque no muero".

No limiar desta análise do criador e sua obra, cabem bem aqui alguns reparos à pessoa intima do homem extraordinário que tive a fortuna de conhecer.

Se me perguntassem sobre qual seria o traço mais marcante do que foi aquela raríssima personalidade, eu responderia: - a vocação da aventura; aquilo que Gustave Flaubert jogava ao espírito medíocre e conformista de seu amigo Maxime du Camp: "o que eu procuro não é o porto, mas o alto mar".

Não seria o alto mar, mas o nosso grande sertão e os mistérios da biota amazônica, tal como expresso no magistral relatório sobre a "Epidemiologia do Vale do Amazonas", que assinará com seu mestre Oswaldo Cruz em 1913, já quatro anos depois da momentosa descoberta no sertão de Minas Gerais.

Coisa parecida iria repetir-se, já com Evandro, seu filho, meu genial classmate na $\mathrm{Fa}$ culdade, quando daquela noite memorável na Academia Nacional de Medicina, então sob a presidência de Miguel Couto, em 1938. Noite em que nos mostrava a imprevista presença de um grave leishmaniose visceral precisamente na Bacia Amazônica, na qual traçava mais uma vez, e com não menor talento e cores, o ambiente ecológico da nova entidade mórbida.

Igual era o talento descritivo, como igual o gosto pela aventura de fazer pesquisa naquelas desamparadas e inóspitas paragens. Ainda me lembro, quando levado a Belo Horizonte atraído pelo então misterioso "Fogo selvagem" aí por 1940, encontrei Evandro escandalizado que lá chegasse eu pela velha ferrovia e com 16 horas de viagem. Por medo do avião, que Charles Richet já estigmatizara com o nome de "neofobia", o avião, essa máquina hoje trivial e que mataria o nosso Evandro aqui mesmo, numa dessas tardes radiosas de maio, naquele ano.

Recuo no tempo e recordo o despontar do ano de 1923 e a partida para a Europa da Missão Centenária de Pasteur, destacando-se além de Mestre Chagas como chefe natural, Eurico Villela e Eduardo Rabello. Muitas recordacões dos feitos e gestos de Carlos Chagas me fi- 
caram guardadas, sobressaindo alguns imprevistos - sempre divertidos - sempre provocados pelos constantes estados de abstração do nosso Chagas, o primeiro dos quais já à partida, a busca nervosa da passagem do ilustre passageiro, afinal encontrada, no porão do navio, e desenterrados os desejados bilhetes do fundo de uma das malas. Já em Paris, outro incidente preocupava o Mestre e mais uma vez divertia os companheiros. Chegava um convite oficial para um jantar no Palácio de Laeken, com o rei Alberto, em Bruxelas. Grande perplexidade para Chagas que assumira para mesma hora e dia um compromisso com Calmette, no Instituto Pasteur. E não foi fácil convencê-lo de que um convite de Rei passava à frente de tudo o mais.

Dias depois, ainda e já em Paris, seria a impressionante cerimônia em honṛa de Pasteur na Sorbonne, sous la Coupole, entre os oradores chamado "Carlos Chagas em nome da América Latina". Enfim, Londres infelizmente sob o calor escaldante de uns dias de julho, com a visita ao Ministry of Health, onde o Cel. James inquiria admirativo: "The great Chagas?" $\mathrm{E}$ uma pouco edificante visita a umas três ou quatro fármacias em busca de piramido, o remédio preferido para as frequentes enxaquecas do Mestre, quando a imprevisível prosódia inglesa da palavra cobria de aflita ansiedade aquele pequeno bando de brasileiros.

Com esta viagem à Europa, iniciaria o nosso grande cientista uma participação pessoal cada vez mais intensa, no plano internacional, a partir da sua designação na qualidade de Membro Latino-americano do Comité de Higiene da Liga das Nações. Seguir-se-ia já na década de 30 , e graças à impressionante liderança de Carlos Chagas, que a Liga das Nações criasse o que viria a ser o Centre Internacional de Leprologie que, aqui no Rio, reuniria mais uma vez Carlos Chagas e Eduardo Rabello num trabalho de intensa pesquisa no campo da hansenologia, que não seria interrompido com a morte prematura do grande homem, antes brilhantemente continuado por Eduardo Rabello até 1939. Lembro-me perfeitamente de uma rápida passagem junto ao Presidente do Comité de Higiene da Liga em 1938, da impressão inesquecível de mestria e eloquência deixada por Chagas entre os sanitaristas de todo o mundo: recordado certo estadista platino do qual se dizia que "vivja em estado de eloquência".

Casos raros na história das coisas da Me- dicina, datam de 1937 a recepção de Carlos Chaga 2 . na Faculdade, e de 1938 e já mencionada famosa intervenção de Evandro Chagas na Academia. Por isso creio que essa esplêndida sucessão de grandes pesquisadores deve levar-nos a rejeitar a idéia expressa por Kretschmer (seu Geniale Menschen) de que "o gênio surgiria na linha hereditária no ponto em que a família muito dotada começa a decair", opinião briIhantemente desmentida por essa rara dinastia de grạndes pesquisadores.

Restaria enquadrar a pessoa desse que foi Carlos Chagas em termos de testemunho, não só os positivos como este mas, e sobretudo, os negativos, neste caso particularmente sugestivos. No primeiro de seus livros, que já constituem um ciclo com que nos brinda sur le tard esse Mestre, senhor memoriaslista e grande escritor que é Pedro Nava, reclama ele contra os biografos, inalteravelmente admiradores dos biografados.

Eis al uma idéia - melhor ditouma posicão que vale ser apreciada, notadamente pelo muito de verdade que encerra. Acodem-me desde logo, contudo, exceções, e elas de resto confirmando a regra, tais os venenosos textos de J. P. Sartre sobre Baudelaire, e os discursos acadêmicos de $P$. Valéry ignorando Anatole France, e o nosso J. Lins do Rego demolindo um ..... gentil predecessor.

Por outro lado, também, a provocadora tese leva-nos a desvendar outro aspecto da questão: quero referir-me a tantos casos em que a biografia leva aspectos francamente críticos seja da pessoa, seja da obra do biografado, quando não se abandonam os aspectos existenciais, por uma acurada critica do estilo. Tudo isso nos induz à idéia do quanto é difícil fugir o biógra. fo da admiração pelo biografado, o que já nos tem brindado com o enfoque não raro brilhante de toda uma época, aqui lembrada a admirável reconstituição de "belle époque" nos volumes de Painter sobre Marcel Proust.

Posso agora chegar ao que chamei de testemunhos negativos, espécie de "guerra fria" movida dentro e fora de Manguinhos, e que culminaria com a agressão lançada em 1926 na Academia Nacional de Medicina. Espetáculo terrivel e que tive o triste privilégio de assistir, de um grande homem a defender-se de um ataque lançado às fibras mais intimas do seu ser: um homem de gênio obrigado a explicar-se como criador, diante da mediocridade incapaz de 
fugir "às regras de sua escola". Foi Baudelaire muito de experiência própria - quem disse num magistral estudo sobre seu amigo Delacroix:

- "o homem superior vê-se obrigado. mais que qualquer outro, a velar pela sua defesa pessoal. Dir-se-ia ver uma sociedade inteira em guerra contra ele". E o sempre lembrado amigo, Otávio Tarquinio, amava recordar uma palavra de Bernardo de Vasconcellos de que "toda superioridade se paga". Assim, de Carlos Chagas, vendo negada a descoberta que seria de Oswaldo Cruz, negado o valor da descoberta do que se pretendia uma desprezivel entidade mórbida, impiedosamente criticada a tese parasitária do bócio endêmico.

Sabemos hoje tudo, ou quase tudo, sobre o problema do bócio endêmico, sem esquecer aquilo de que "os grandes homens nos ensinam tanto com seus erros que com suas descobertas". Em imunologia, por exemplo, ninguém se atreveria hoja a menosprezar a controvérsia entre Coca e Doerr, ai pelos idos dos anos 20, porque não sabiam ambos explicar o caso limite da alergia ao Ascaris, explicada já nessa época como alergia reagínica, e portanto vizinha da atópica, por Wernel Jadassohn em seus clássicos experimentos sobre o assunto.

No caso particular de Carlos Chagas, o extraordinário impulso que a longo prazo - mais precisamente entre 1909 e 1939, a principio com Eurico Vilella, mais tarde nas mãos de Evandro Chagas e Emanuel Dias no Brasil, de Salvador Mazza, Romaña e outros na Argentina - levou a tremendos avanços no conhecimento da Tripanosomíase americana. Entre outros, e já a partir dos anos 60, a integração do "mal de engasgo" e o mega-esófago, graças aos trabalhos da Escola de Ribeirão Preto. Para muito além disso, uma onda de fertilização se estendendo a todo o campo das ciências médicas e biológicas em nosso País, período de máximo fastígio do Instituto Oswaldo Cruz, seus pesquisadores, seus mestres. Enfim, recordada ao longo dos anos 30 e 40 , os resultados obtidos com a reformulação de nossa política sanitária, conse quência da famosa Lei Carlos Chagas de 1921 . 1923.

Muito diferente do que ocorre na criação artística, o homem de ciência, em seu trabalho, em especial o biologista e médico, não opera "substituindo" o dado natural pelo que vai criando - antes, criando sobre os dadós que Ihe são oferecidos pela natureza. Com isso, o cientista-pesquisador marca sua independência quanto ao mundo exterior, emprestando aos processos mentais em elaboração um caráter artístico de introversão.

Muito diferente também da criação artística, a criação científica não opera dando ao dinamismo interior preponderância sobre os dados colhidos no mundo exterior. Bem ao contrário, o cientista-pesquisador vê despertada sua imaginação em estreito contacto com o mundo exterior, o que se acompanha de uma exacerbação, não de anestesia de seus dons de percepção. Nada de agitaçâo e de estados sonambúlicos, nada do "primitivo e santo terror", alegado por $H$. de Balzac, nada de famosa crise de "sonolência" ao embalo da qual Richard Wagner concebeu o celebrado acorde em mi bemol maior que abriria o Rheingold. Em tudo isso, agudo contraste com a rígida e impecável maîtrise dos arroubos da afetividade, serena caracteristica do sábio em trabalho de pesquisa, buscando e encontrando em sua vida interior a "grandeza tranquila" própria dos criadores.

Entretanto, ocorrem também analogias como, por exemplo, com o que Rusu (seu Création artistique) denomina o "momento central da inspiração", que em seu ponto culminante revela o caráter de espontaneidade com que surge a idéia "matriz". Flaubert disse: "une idée mère d'oú toutes les autres découlent". Aqui intervem, poderosa, a imaginação criadora da invenção, mais ou menos complexa, e de uma atitude mental comandada do exterior. E de novo é Rusu quem diz e muito bem que "a tensão interior persiste e é ela quem dá vida à imaginação".

No caso particular de Chagas, e já o preveniu lindamente Keyserling (seu Méditations sud-américaines), é muitas vezes uma experiência exterior que "pode criar a tensão, quando ela ainda não existe, e deslanchar do mesmo passo a criatividade". Lembrado Goethe quando certa vez disse que era só "preparar a lenha $e$ deixá-la ficar bem seca, depois é vê-la pegar fogo para nossa surpresa".

Entretando, ao cientista-pesquisador não lhe faz tamanha e anterior "riqueza de experiência": tudo se passa como se em dado momento a criação nele explodisse" (alguém já disse desse momento tratar-se de um "subliminar uprush"), 
Antes de deter-me com maior minúcia na análise da dinâmica da descoberta, vou agora sublinhar com intenção tudo que, nesse domínio, devemos à imaginação e à teoria: e aqui Baudelaire - "a imaginação, rainha das faculdades mentais". Sei, e muito bem, um pouco por experiência própria, quanto costumam trazer de pejorativo as palavras "imaginação" $\mathbf{e}$ "teoria". Sei, entretanto, também que aos grandes Mestres das Ciências Médicas jamais faltou exaltada referência a essas duas posições do espírito.

Disse Claude Bernard: "Quando se entra em terreno novo não há temer emitir vistas mesmo aventuradas, a fim de excitar a pesquisa em todas as direções". E lapidarmente também isto: "os fatos são materiais necessários; mas é a utilização deles pelo raciocínio experimental isto é a teoria, que em verdade constitui e edifica a ciência".

Por mais de uma vez tenho lembrado que nem só de fatos vive a ciência, mas também de imaginação e teoria. É ainda Bernard que recomenda "dar largas à imaginação, e que năo há de esquecer que a teoria ilumina a prática, e a prática deve por sua vez servir à ciência". Quase as mesmas palavras usaria J. Jadassohn muito mais tarde dizendo que "a prática melhora a teoria e a teoria a prática". Sirvo-me com intenção do grande nome de Jadassohn porque ele também sofreu em vida a pecha de "teórico" e "imaginativo", sem embargo de suas geniais antecipações, como por exemplo fundando a nossa moderna Dermatologia funcional, e construindo toda uma teoria da Hanseníase, com base em um escasso caso da forma tuberculóide.

Aqui, as noções de movimento e de intenção manifesta se impõem traduzindo o dinamismo dos processo mentais da criatividade - o nome de Husserl aqui lembrado. E é bem matéria inteiramente nova que a imaginação criadora oferece no campo da criação científica, e lhe dá - cunho de originalidade na riqueza de suas combinações.

Nesse sentido, a imaginação criadora tira seu poder de liberação das próprias limitações do mundo exterior, da capacidade de recriar $\mathbf{e}$ de recompor os dados do meio exterior, em vista da criação de algo inteiramente novo. E é quase um milagre que o homem de ciência possa criar o novo, apesar de sujeito no sentido que empresta ao meio exterior.
É conhecida a clássica diferença proposta por Ribot (seu Imagination créatrice) entre a imaginação intuitiva e reflexiva. A distinção é de valor conhecido em certos casos - mesmo assim não todos, da criação em arte. No caso, porém, do cientista-criador, e muito em especial no caso do nosso genial patrício, parece difícil separar as duas coisas. Para quem teve a fortuna de conhecer a Chagas de perto, era transparente a força e intensidade de uma certa "efervescência interior" própria dos intuitivos. Contudo, é sobretudo como esforço de elaboração que a sua imaginação operava. Lembrado aqui o famoso preceito, creio de Edison, de que gênio é "noventa por cento transpiração, e dez por cento inspiração" - e que também se encontra num passo de Flaubert quando escreveu na sua Correspondance de que uma obra se faz "à custa de desassossego, tempo e suor".

Nesse contexto, o trabalho de elaboração atinge seu ponto culminante quando o cientistacriador assume uma "atitude crítica". Isto ocorreu no curso da descoberta da Tripanosomiase Americana quando Chagas deparou com as formas de Critidia no intestino posterior de um certo hematófago que infestava as pobres habitações da região: "Esta verificação", recordou ele, "conduziu-me a duas hipóteses - ou seria o flagelado observado parasito natural do inseto, sem qualquer ação patogênica, ou representaria estadio de hemoflagelado de vertebrado, quiçá do próprio homem".

Não há melhor maneira, creio, de apresentar essa face característica da elaboração da descoberta: a escolha entre duas opções, o fulcro de todo o processo criativo, que Nietzche diria "passar ao crivo" do juizo, subjugada a idéia mestra a fim de organizar tudo em torno dela, agrupando os fatos até então observados e dando-Ihes a necessária sequência - o criador intervindo a todo o momento, e guardando a iniciativa da decisão.

Elaboração carregada de intenção, desejada por motivo desse espírito de ordem que o mesmo Nietzche (seu Humano demasiado humanol noutro passo atribui, com muita propriedade à "robusta consciência de artesão". No caso particular do criador científico, o processo de criação tem na crua realidade o seu material de trabalho; de sorte que a finalização coincide, pela maior parte, com a elaboração de um plano sempre extremamente simples. E esse plano nasce assim diretamente em estreito con- 
tacto - não raro apesar de - com a realidade, de/ composta e recomposta ao longo do processo. Atitude que Paulhan (sua Psicologia da invenção) denomina de "desenvolvimento por evolução". Também, e à diferença com a criação em Arte, não necessita o pesquisador criador de lastro cultural especial. Lembrado Newton quando inquirido sobre a descoberta da gravitação respondeu: "foi pensando sempre nela", ou o austero gabinete de trabalho de Einstein em Princeton, onde não havia livros e sim uma série de cachimbos.

Radicalmente diverso também do que ocorre na criação em Arte, é o reencontro com o material e com os problemas da técnica - que são finais para o artista, enquanto marcam o início do processo da criação científica. E aqui se inscreve algo de profundamente original na descoberta da Tripanosomiase Americana: a identificação do parasito, antes de conhecida a moléstia que ele provocava. Justamente porque o pesquisador dominava todos os segredos da técnica e o sentido contido no material de trabalho, pode ele realizar e levar a cabo a grande obra que a ele se oferecia.

Fase capital da descoberta e que, na palavra de Chagas, era uma hipótese de trabalho que "retirava do descobrimento da nova doença qualquer aspecto de mero acaso" - foi a premonição, a intuição de que nas zonas infestadas pelo novo hematófago, quadros mórbidos até então não identificados bem podiam ser a expressão patogênica do flagelado, portado por aquela espécie de inseto próprio da região.

De af por diante, $o$ lento trabalho de elaboração, a partị do primeiro caso agudo da moléstia, aos crônicos, à descoberta necrópsica da forma cardiaca e as curiosas formas leishmania do parasito nos tecidos, a penetração pela pele integra mercê das formas metaciclícas, e que Romaña identificaria muito mais tarde como Chagoma de inoculação.

Descartado, destarte, qualquer aspecto singular de brusca iluminação ou de "inspiração" pura e simples na descoberta, ainda sobram aspectos, dir-se-ia divinatórios. Quero referir-me à identificação de um hospedeiro selvagem na infestação do tatu ou armadilho - então Tatusia, hoje Dasypus novemcintus, no qual via Chagas um dos portadores de uma zoonose, a nova Tripanosomíase, eventualmente patogênica para o homem.
Apontando a infestação desse edentado e sua eventual importância para a moléstia humana, Chagas deixaria para nós, pesquiisadores brasileiros, uma mensagem - crftica é certo, mas divinatórịa. Datam de 1971 as pesquisas da norte-americana Storrs mostrando no nosso tatu o animal de escolha - afinal encontrado! para a obtenção da forma maligna de Hanseníase. Faltou-nos a nós, habitantes da planície - já que "tudo é ousado para quem a nada se atreve" - esse dom quichotesco já apontado por Richet como próprio dos grandes descobridores, mais afeitos às altas e rarefeitas regiões da genialidade.

Ainda refletindo no problema da criação em ciência, e no plano especulativo, vemos ocorrer nova coincidência com o processo criador em Arte quando a mão do criador "no abstrato cria o concreto e no imponderável, o peso". É a mesma "luta" com o material a fim de que se opere a captação nele da idéia elaborada mercê da técnica, e o processo venha a ter sequência com o imenso esforço de dar vida, e um sentido novo, ao material de trabalho cujas "lei próprias" irão sendo desvendadas.

Em termos mais poéticos, é a lição de Fernando Pessoa quando propõe unir "por instinto as duas formas de cultura: criando como artistas, sabendo como sábios, porém em um só ato; pois o que criam, o criam inteiramente como verdade, que não como criação; e o que sabem, o sabem inteiramente, porque não $o$ descobriram mas criaram". Tiro aqui do pequeno e precioso livro de C. P. Snow "The two cultures", isto de que os homens de ciência como que "têm por temperamento o futuro no sangue", e de que a ciência aplicada não é "um domínio reservado aos espíritos medíocres". $\mathrm{Na}$ verdade, todo o bem de que é capaz a ciência aplicada reflete algo de mais árduo, de maior soma de qualidades humanas, e ao cabo igual capacidade de liberar e enriquecer o espírito humano, em todas as dimensões a seu alcance.

Mais do que qualquer um, o homem de ciência vive na repercussão do conhecimento do mundo das coisas, na medida em que "se alimenta do universo" à sua volta, e da conquista da realidade mercê dos conceitos, em última análise de sua visão do mundo. Mas é em certos homens privilegiados que existe para a inteligência uma "outra espécie de vida", a liberdade de trabalhar o pensamento lógico não raro livre das leis que regem a razão discursiva, e a verifi- 
cação cientifica dos fatos trabalhados. Esse dado individual que é a intuição, levando à liberdade de criar, promove nas belas palavras de Maritain “esta delectação espiritual que libera os homens do seu eu material, e os eleva até o conhecimento experimental". E do mesmo, que "na raiz do ato criador deve haver um processo intelectual todo peculiar, uma espécie de experiência ou de conhecimento sem paralelo na razão lógica. . .": "uma profunda reserva ociosa do espírito é como um sono da alma, mas sendo do espírito está num estado de vigilância e de tensão vital".

Sob certos aspectos, aproxima-se o homem de ciência no que respeita ao ato de criar mais do pintor do que qualquer outro artesão, porque também é um "cativo da natureza cujas vias interiores de operação e reservas de revelação" procura interpretar, desvendado os "inesgotáveis aspectos interiores do material visivel".

Um outro aspecto do processo de criacão é também belamente apresentado por Maritain sob o título de a "inocência de Dante" em que o nosso filósofo procura as profundas reservas da alma onde tem suas raízes o poder criador - "a inocência criadora", em suas duas conotações de ingenuidade e incorruptibilidade. Já é quse um truísmo dizer que o gênio é o reencontro com a infância, mas esta inocência criadora nem sempre coincide com a inocência moral, e sim caractęriza uma espécie de integrifade original, básica em certas pessoas marcadas pela grandeza, ficando a obra criada inaccessivel mesmo à eventual corrupção do criador. Assim se explica - pelo menos assim me parece, a intransigência de sábios e artistas exclusivamente no que respeira à obra, lembrados por exemplo a servilidade de Cuvier ou as baixesas de Hegel, sem influência na grandeza de seus trabalhos.

Intuir: e mesmo advinhar o que vem contido no material, faz parte do processo da descoberta e, neste caso, o significado dos hábito domiciliários do transmissor levaria, pela primeira vez na história das moléstias, à notabiÍ́ssima sequência, parasito: transmissor: moléstia. Pelo que, Rusu diz, e diz muito bem que o processo criador contem dois aspectos. De um lado a concentração interior sobre uma visão e o esforço por torná-la visível, de outro lado a constante repercussão da obra sobre o seu autor. E dessa maneira, ampliando sempre os horizontes do criador.

Não vejo, entretanto, como se possa se- parar, em termos de pesquisa científica, os tipos de criador já denominados de /chdichter ou seja - que se mantem no primeiro plano, e Sachdichter - aquele que deixa que os fatos e situações falem por si. Também é difícil admitir influências "coletivas", quando se pensa no milagre deste criador em meio ao ambiente acanhado e decididamente nada estimulante neste País, e nesta Cidade, nos primeiros anos deste século. E o pensamento vai a outro desses milagres, aquele que teve por nome Machado de Assis . . .

Entretanto, e no tocante a Carlos Chagas, surge, dominante, a presença e o exemplo de Oswaldo Cruz, atuando no momento certo, criando uma Escola de pensamento, o que alguém já chamou de apprenticeship of greatness, criando uma atmofesra adequada ao processo criador, e podendo ter influído, no então pequeno grupo de fiéis, também sobre o genial descobridor da Tripanosomíase Americana. Aqui também, mais uma analogia com a criação em Arte, lembrada por exemplo a atmosfera que envolveu certa vez Baudelaire, Delacroix e Rich. Wagner, em Paris, com maior amplitude ainda no que se chamou nos anos 10 e 20 deste século a Escola de Paris, seus pintores, poetas e músicos.

Termino aqui isto que, prometido ensaio, saiu-me diminuido pelas limitações impostas pela grandeza do modelo contemplado. Ao grande homem, e maior brasileiro que foi Carlos Chagas, cabem con justiça estes versos de Gautier, aqui reproduzidos com a chancela de Baudelaire:

"Il naît sous le soleil de nobles créatures Ne leur donnez qu'un jour ou donnez-leur cent ans

I/s meneront à bout leurs destins écla. tants".

\section{NOTAS A CORREÇÃO DO TEXTO}

Quando dessa exposição sobre Carlos Chagas foram apresentados e por pessoas do mais alto gabarito, alguns reparos à minha posição, entre eles:

1 - que Chagas não teria sido movido pelo "gosto da aventura";

2 - que o ambiente técnico-científico já era muito avançado entre 1900 a 1910 , nesta cidade; 
3 - e enfim que talvez fosse Chagas um clínico antes de tudo.

ad 1 - Além da imagem literária, a descoberta de Chagas não foi apenas o que se costuma chamar de uma "aventura do espírito".

Pessoa ligada - como foi Miguel Pereira ao "terroir", e intimo do nosso interior, o então jovem Carlos Chagas não podia fugir à atração do solo nativo. Explicando-se assim seja na biota amazônica, seja no sertão de Minas, que foi realmente o gos to ou a vocaçäo da aventura que muito facilitou a interiorização do genial pesquisador.

ad 2 - Também me parece fora da dúvida ter sido bem acanhado, na antiga capital, o nível técnico-científico na 1 ạ década deste século.

Não ignoro, é claro, os grandes "clínicos" que foram Torres Homem, Francisco de Castro, Rocha Faria e outros. Mas era uma clínica quase não acompanhada da conotação investigativa que hoje a caracteriza.

Lembro-me, por exemplo, de ter ouvido a
Eduardo Rabello "declamar" trechos da então famosa Propedeutica Médica de Francisco de Castro, tal a a beleza em que era vazada.

Na verdade, houve 2 exceçōes - Miguel Couto e Carlos Chagas. Mas em niveis radicalmente diferentes.

.Em Miguel Couto, uma continuação da Escola Francesa de Laennec e Charcot, ou seja a correlação anatomo-clínica.

Ao contrário, em Chagas, já se trata claramente da moderna clínica investigativa, inaugurada por ele nesta cidade, e neste Pais.

ad 3 - Enfim, não me parece verdade que tenha sido Chagas, acima de tudo, um clínico genial. Posto que com ele ocorreu justamente o inverso - ou seja, a incursão de um homem de gênio nos domínios da clínica, juntamente com os achados da protozoologia, as evidências da ecologia, as minúcias da entomologia e da anatomia patológica que, pela primeira vez neste País, mostrava ligadas. Tudo isto, transmitido com aquela genialidade que the era própria. 